\title{
The influence of particle composition upon the evolution of urban ultrafine diesel particles on the neighbourhood scale
}

\author{
Irina Nikolova ${ }^{1}$, Xiaoming Cai ${ }^{1}$, Mohammed Salim Alam ${ }^{1}$, Soheil Zeraati-Rezaei ${ }^{2}$, Jian Zhong ${ }^{1}$, \\ A. Rob MacKenzie ${ }^{1,3}$, and Roy M. Harrison ${ }^{1, a}$ \\ ${ }^{1}$ School of Geography, Earth and Environmental Sciences, University of Birmingham, Edgbaston, Birmingham B15 2TT, UK \\ ${ }^{2}$ Department of Mechanical Engineering, University of Birmingham, Edgbaston, Birmingham B15 2TT, UK \\ ${ }^{3}$ Birmingham Institute of Forest Research (BIFoR), University of Birmingham, Edgbaston, Birmingham B15 2TT, UK \\ aalso at: Department of Environmental Sciences, Center of Excellence in Environmental Studies, King Abdulaziz University, \\ P.O. Box 80203, Jeddah, 21589, Saudi Arabia
}

Correspondence: A. Rob MacKenzie (a.r.mackenzie@bham.ac.uk)

Received: 1 November 2017 - Discussion started: 16 January 2018

Revised: 19 September 2018 - Accepted: 12 October 2018 - Published: 5 December 2018

\begin{abstract}
A recent study demonstrated that diesel particles in urban air undergo evaporative shrinkage when advected to a cleaner atmosphere (Harrison et al., 2016). We explore, in a structured and systematic way, the sensitivity of nucleationmode diesel particles (diameter $<30 \mathrm{~nm}$ ) to changes in particle composition, saturation vapour pressure, and the mass accommodation coefficient. We use a multicomponent aerosol microphysics model based on surrogate molecule $\left(\mathrm{C}_{16}-\mathrm{C}_{32}\right.$ $n$-alkane) volatilities. For standard atmospheric conditions (298 K, 1013.25 hPa), and over timescales (ca. $100 \mathrm{~s}$ ) relevant for dispersion on the neighbourhood scale (up to $1 \mathrm{~km}$ ), the choice of a particular vapour pressure dataset changes the range of compounds that are appreciably volatile by two to six carbon numbers. The nucleation-mode peak diameter, after $100 \mathrm{~s}$ of model runtime, is sensitive to the vapour pressure parameterisations for particles with compositions centred on surrogate molecules between $\mathrm{C}_{22} \mathrm{H}_{46}$ and $\mathrm{C}_{24} \mathrm{H}_{50}$. The vapour pressure range, derived from published data, is between $9.23 \times 10^{-3}$ and $8.94 \times 10^{-6} \mathrm{~Pa}$ for $\mathrm{C}_{22} \mathrm{H}_{46}$ and between $2.26 \times 10^{-3}$ and $2.46 \times 10^{-7} \mathrm{~Pa}$ for $\mathrm{C}_{24} \mathrm{H}_{50}$. Therefore, the vapour pressures of components in this range are critical for the modelling of nucleation-mode aerosol dynamics on the neighbourhood scale and need to be better constrained. Laboratory studies have shown this carbon number fraction to derive predominantly from engine lubricating oil. The accuracy of vapour pressure data for other (more and less volatile) components from laboratory experiments is less critical. The influence of a core of non-volatile material is
\end{abstract}

also considered; non-volatile core fractions of more than $5 \%$ are inconsistent with the field measurements that we test the model against. We consider mass accommodation coefficient values less than unity and find that model runs with more volatile vapour pressure parameterisations and lower accommodation coefficients are similar to runs with less volatile vapour pressure parameterisations and higher accommodation coefficients. The new findings of this study may also be used to identify semi-volatile organic compound (SVOC) compositions that play dominating roles in the evaporative shrinkage of the nucleation mode observed in field measurements (Dall'Osto et al., 2011).

\section{Introduction}

Ultrafine particles (UFPs, with particle diameter $D_{\mathrm{p}}<$ $100 \mathrm{~nm}$ ) have become an increasingly important focus of urban air research over the last 2 decades. The main source of UFPs in outdoor urban air is typically road traffic (Kumar et al., 2014). Harrison et al. (2011) reported that on a busy highway in central London, UK, $71.9 \%$ of particles by number were traffic-generated; of this $71.9 \%, 27.4 \%$ were found in the semi-volatile exhaust nucleation mode (size between 15 and $30 \mathrm{~nm}$ ), $38 \%$ were in the exhaust solid mode (size > $30 \mathrm{~nm}$ ), and the remaining $6.5 \%$ were from brake dust and resuspension (size $>2000 \mathrm{~nm}$ ). Hereafter, nucleation-mode particles are defined as particles with a diameter of less than 
$30 \mathrm{~nm}$, whilst Aitken-mode particles have a diameter in the range of $30-100 \mathrm{~nm}$. Health-related research - prompted by the proximity of the UFP traffic source to the public, and the large number of UFPs emitted by traffic - has accrued evidence pointing to the toxicity and potentially harmful effects of UFPs on human health (Atkinson et al., 2010). Experimental and modelling studies have advanced our understanding of the behaviour of urban air UFPs, e.g. the relevant aerosol dynamics important to the evolution of UFPs in space and time (Jacobson, 2005; Allen et al., 2007; Biswas et al., 2007; Dall'Osto et al., 2011; Nikolova et al., 2011; Karnezi et al, 2014; Karl et al., 2016).

Nonetheless, key information regarding the size-resolved composition of UFPs is missing, which limits our ability to determine the impact of gas-transfer processes on UFP evolution. Progress has been made in modelling traffic-generated particles (including the ultrafine fraction) using a volatility basis set, defined using the effective saturation concentration (Donahue et al., 2006). Progress in identifying the precise chemical composition of traffic-generated particles has been made by resolving the so-called "unresolved complex mixture" (largely uncharacterised organics in traditional gas chromatography) via two-dimensional gas chromatography (GC $\times$ GC; Chan et al., 2013). Alam et al. (2016) show that emitted ultrafine diesel particles consist of a substantial amount of organic material from both unburnt diesel fuel and engine lubricating oil. They attribute the low-molecularweight semi-volatile organic compounds (SVOCs, with a carbon number $<18$ ) predominantly to unburnt diesel fuel, whereas heavier SVOCs (carbon number $>18$ ) are attributed predominantly to engine lubricating oil. A typical GC $\times \mathrm{GC}$ separation is shown in the chromatogram (Fig. 1) for diesel engine exhaust emissions in the particulate-phase Aitken mode $\left(56<D_{\mathrm{p}}<100 \mathrm{~nm}\right)$. Compounds are separated by volatility along the $x$ axis (first separation dimension) and by polarity in the $y$ axis (second dimension). Peak identification is based on retention indices and mass spectral data from the National Institute of Standards and Technology (NIST) library. The majority of chromatography peaks (identified as aliphatic alkanes, lower black polygons) are present between $\mathrm{C}_{18}$ and $\mathrm{C}_{26}$, corresponding to the compounds identified in the engine lubricating oil and particulate phase engine emissions (Alam et al., 2017). Bar charts above the chromatogram show the volatility distribution of total alkanes (red) and total identified compounds (black), indicating that, although many hundreds of individual chemical compounds are detected, the majority of SVOC emissions consist of alkanes. Both the alkane composition and the total composition distributions show a broad peak centred at $\mathrm{C}_{25}$.

Most primary organic particle emissions are semi-volatile in nature; thus, they are likely to evaporate due to atmospheric dilution and increased distance from the source (Robinson et al., 2007). This was observed by Dall'Osto et al. (2011; Fig. S1 in the Supplement) as part of the REPARTEE campaign (Harrison et al., 2012). Dall'Osto et al. (2011) reported a remarkable decrease in the measured nucleationmode peak particle diameter $\left(D_{\mathrm{pg}, \text { nuc }}\right)$ between a street canyon $\left(D_{\mathrm{pg}, \text { nuc }}=23 \mathrm{~nm}\right)$ and the downwind neighbourhood $\left(D_{\mathrm{pg}, \mathrm{nuc}}=8-9 \mathrm{~nm}\right)$ that were located ca. $650 \mathrm{~m}$ from one another in central London (UK). The travel time, depending on the wind speed, can vary from $\sim 100$ to $\sim 300$ s. Nucleation formation of new particles in the atmosphere was ruled out as a possible reason for the observed behaviour. Instead, the decrease in particle diameter was attributed to the effect of evaporation and substantial mass loss from the particle surface (hereafter referred to as REPARTEE-like aerosol dynamics). Alam et al. (2016) present the composition of diesel UFPs measured on a laboratory test-rig (cf. Fig. S2); however, the range of variability of the particle composition in emissions is still unknown. It is also not known how the organic material is distributed onto the nucleation and Aitken modes of the UFP distribution in the atmosphere.

Numerical experiments can test the plausibility of possible missing components of the system, and can advise on which experimental studies will be most likely to resolve the existing knowledge gaps. Nikolova et al. (2016) describe a modelling framework that can produce nucleation-mode dynamics consistent with observations. However, missing in that study, which was carried out before the test-rig experimental results (Alam et al., 2016, 2017) were available, is a systematic sweep of critical thermodynamic parameters and a size-resolved composition that could determine or point to REPARTEE-like aerosol dynamics.

In the present study, in an extensive new set of model runs moving beyond Nikolova et al. (2016), we develop a method to search the particle composition space - i.e. the volatility parameter space - to identify a group of surrogate $n$-alkanes in the $\mathrm{C}_{16} \mathrm{H}_{34}-\mathrm{C}_{32} \mathrm{H}_{66}$ range that could explain a decrease in the nucleation-mode particle diameter to $10 \mathrm{~nm}$ or below, as seen in the measurements in London (Dall'Osto et al., 2011). The model simulations are focused on events after dilution and cooling of the exhaust-pipe plume. We provide a more robust approach to identify crucial parameters responsible for the UFP behaviour in the atmosphere on the neighbourhood scale including the identification of parameter sets that are incompatible with the observed behaviour of nucleationmode UFPs in urban air. We describe a new way of simulating and evaluating the role of the SVOC composition on the atmospheric behaviour of the size-resolved urban UFPs and examine more complex sets of compositions involving a non-volatile core. We extend our model run set to assess the critical and interacting roles of the saturation vapour pressure parameterisation and the mass accommodation coefficient on the size-resolved aerosol dynamics.

In this study we use Lagrangian box-model simulations of the evolution of urban ultrafine diesel particles on the neighbourhood scale (up to $1 \mathrm{~km}$ ). Key results are presented and discussed in the main body of the text, whilst more details are provided in the Supplement. Section 2 describes the modelling approach, Sect. 3 presents the model output, and 


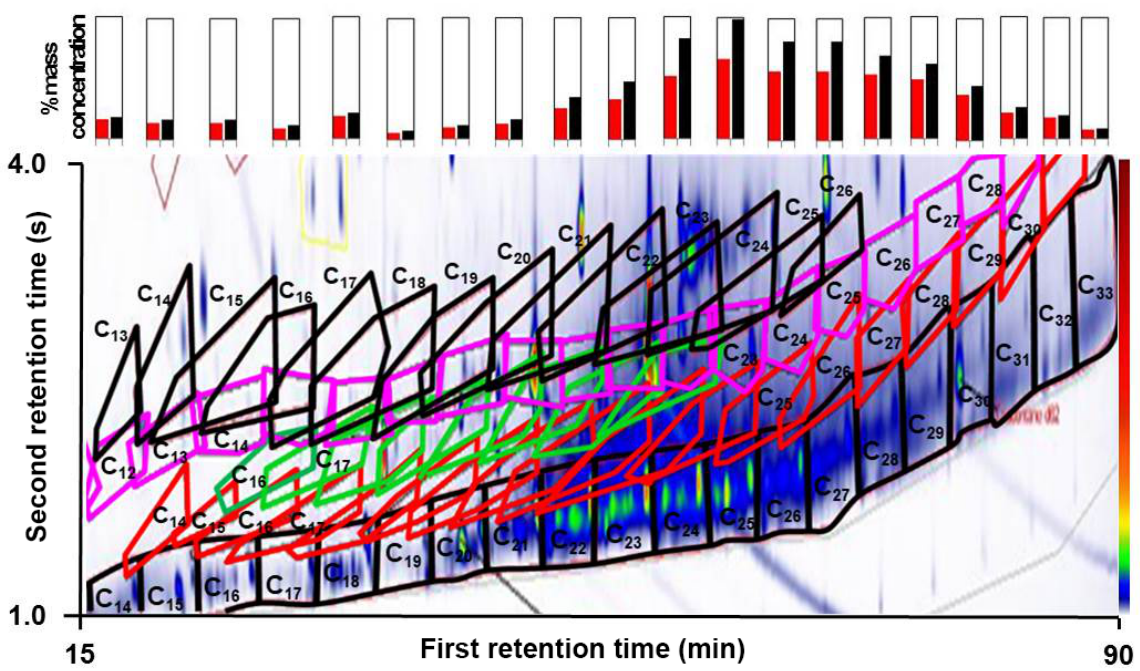

Figure 1. A GC $\times$ GC chromatogram (contour plot) indicating homologous series of compounds identified in diesel engine exhaust emissions. Emissions from a light-duty diesel engine operating at 1800 revolutions per minute and 1.4 bar brake mean effective pressure. Compounds identified in the contour plot are indicated by the coloured polygons - lower black polygons are $n+i$-alkanes; red polygons are monocyclic alkanes; green polygons are bicyclic alkanes; pink polygons are aldehydes + ketones; and upper black polygons are monocyclic aromatics. Each peak in the contour plot represents a compound present in the emissions; warmer colours (e.g. red) are more intense peaks while colder colours (e.g. blue) are smaller peaks. The contour plot were produced by GC Image v2.5. The bar charts above the contour plot show the volatility distribution of total alkanes (red) and total identified species (black), indicating that the majority of the emissions consist of alkanes. For details of the compound attribution method, see Alam et al. (2017).

Sect. 4 summarises the key findings and outlines suggestions for further work.

\section{Methodology}

We adopt a "surrogate molecule" approach to UFP composition, based on the chemical speciation shown in analyses such as Fig. 1. The composition of UFPs is simulated as comprising $n$-alkanes from $\mathrm{C}_{16} \mathrm{H}_{34}$ to $\mathrm{C}_{32} \mathrm{H}_{66}$, which are the most abundant compounds in Fig. 1. Previously (Nikolova et al., 2016), we initialised the $n$-alkane abundance in gas and particle phases in a different way, using roadside and urban background observations in Birmingham, U.K. (Harrad et al., 2003). In the following, we retain this roadside gas-phase initialisation (see below), but choose a more general method for initialising the particle composition, in order to test the sensitivity of the results to the initialisation in a systematic way. By adopting a surrogate molecule approach, we are effectively anchoring our model volatility basis set in physico-chemical data, as discussed further below.

The SVOC mass fractions in a particle are represented by a truncated Gaussian distribution that is centred for each model run at a given $n$-alkane in the range from $\mathrm{C}_{16} \mathrm{H}_{34}$ to $\mathrm{C}_{32} \mathrm{H}_{66}$ with a standard deviation, $\sigma$, varying from 1 to 5 . In the following we call the surrogate $n$-alkane on which the composition distribution is centred, the "modal composition". Example compositions are shown in Fig. 2 for a Gaussian dis-

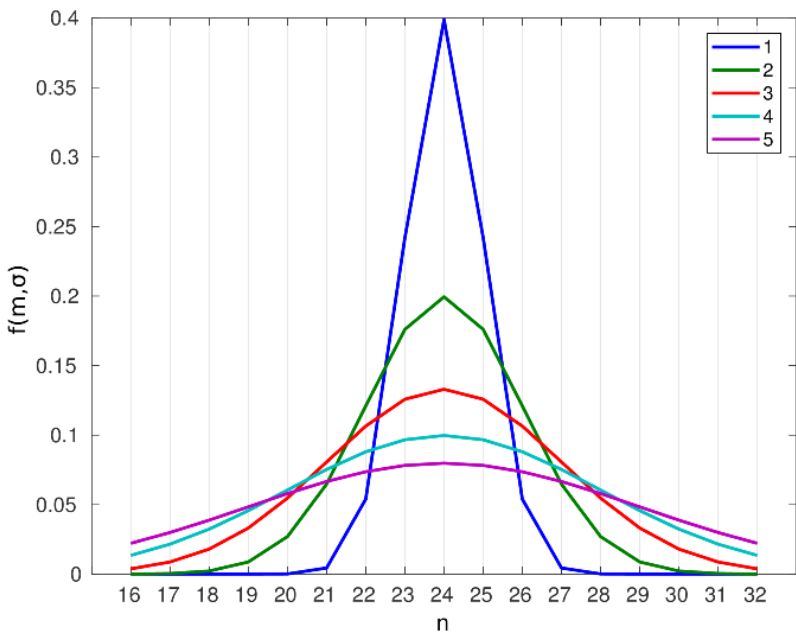

Figure 2. An example of nucleation-mode UFP compositions, represented as mass fractions for surrogate compounds $\mathrm{C}_{n} \mathrm{H}_{(2 n+2)}$, $n=[16: 32]$, and described by a Gaussian distribution centred on $\mathrm{C}_{24} \mathrm{H}_{50}$ with a standard deviation, $\sigma$, from 1 to 5 .

tribution centred at $\mathrm{C}_{24} \mathrm{H}_{50}$. A narrower mass distribution, with $\sigma=1$, focuses predominantly (ca. $40 \%$ ) on the component, $j\left(\mathrm{C}_{24} \mathrm{H}_{50}\right)$, at which the distribution is centred, with a smaller (ca. $24 \%$ ) contribution from the adjacent compounds $\mathrm{C}_{23} \mathrm{H}_{48}$ and $\mathrm{C}_{25} \mathrm{H}_{52}$, and a minor contribution (ca. $5 \%$ ) from 
$\mathrm{C}_{22} \mathrm{H}_{46}$ and $\mathrm{C}_{26} \mathrm{H}_{54}$. The contribution of the remaining compounds from the tail of the distribution is very low (less than $1 \%$ ). However, a wider mass distribution (e.g. $\simeq 5$ ) approximates a flat distribution and includes a contribution from the majority or all of the compounds in the $n$-alkane range from $\mathrm{C}_{16} \mathrm{H}_{34}$ to $\mathrm{C}_{32} \mathrm{H}_{66}$. Monotonically decreasing distributions occur for distributions centred at either end of the $\mathrm{C}_{16} \mathrm{H}_{34}$ to $\mathrm{C}_{32} \mathrm{H}_{66}$ range. Overall, if one excludes the compounds with less than a $1 \%$ contribution, modal compositions centred at carbon number, $j$, with $\simeq 1,2,3,4$, and $5 \sigma$, contain surrogate compounds $\pm 2,4,7,9$, and 11 carbon numbers of $j$ (formally, to remain in the 16-32 carbon number range, $[\max (16, j-2), \min (32, j+2)],[\max (16, j-4), \min (32$, $j+4)],[\max (16, j-7), \min (32, j+7],[\max (16, j-9)$, $\min (32, j+9]$, and $[\max (16, j-11), \min (32, j+11)])$, respectively. Multi-modal compositions, or other compositions differing strongly from Gaussian, are not investigated in the present study, but could be accommodated by a simple extension of the method.

We use a Gaussian distribution to represent the composition of the particles because it provides a structured and systematic way to evaluate the organic-aerosol phase partitioning and the amount of organic matter in the UFP. This is important for the behaviour and evolution of the UFP at various timescales relevant for the urban atmosphere. Although there is no reason to discount other functional forms for the composition distribution (e.g. skew Gaussian, log-normal, Pareto, linear, among others), the Gaussian distributions chosen represent a simple two-parameter approach to explore the volatility/composition space available.

\subsection{Box model}

The model used in this study is the UFP version (Nikolova et al., 2016) of CiTTy-Street (Pugh et al., 2012); that is, a box-model configuration that accounts for the multicomponent nature of the urban ultrafine particles. The CiTTy-Street UFP model is used with 15 discrete size bins, with an initial diameter range between 5.8 and $578 \mathrm{~nm}$ in a uniform logscale. The model can operate in two modes with respect to the aerosol dynamics: Eulerian (fixed particle-diameter grid) or Lagrangian (moving particle-diameter grid). The Eulerian mode is selected when the UFP size distribution is evaluated in the presence of emissions and exchange of particles between spatial boxes (Nikolova et al., 2016). The Lagrangian mode can be selected when the UFP size distribution is evaluated for an isolated air parcel, i.e. when no emissions or transport between spatial boxes are present. In this study, the Lagrangian mode is selected in a zero-dimensional configuration with no emissions or transport in/out of the box. The UFP dynamics (only condensation/evaporation) are simulated such that particles are allowed to grow/shrink to their exact size without any redistribution onto fixed bins in a grid with bin bounds left open in a fully moving diameter scheme (see, for example, Jacobson et al., 1997). Our earlier work
(Nikolova et al., 2016) showed that deposition and coagulation have a minor effect in the current scenario, and so these factors were switched off to allow a more straightforward diagnosis of model behaviour. The condensation/evaporation process applies Raoult's law (for an ideal solution of the volatile compounds) and a default mass accommodation coefficient $\alpha=1$ (Julin et al., 2014) for all SVOCs. The effect of changing $\alpha$ is investigated in Sect. 3.4. The Kelvin effect is also considered, which alters the saturation vapour pressure of the compounds as a function of the particle diameter, the surface tension of the SVOC mixture/solution, and the molecular weight of the participating compounds. The Kelvin effect is pronounced for particles with a diameter less than $20 \mathrm{~nm}$ and substantial for particles with diameter less than $10 \mathrm{~nm}$. The Kelvin term accelerates the evaporation for all compounds under consideration in this study and more notably for the high-molecular-weight compounds due to their larger molar volume.

The model results are evaluated at 1,10 , and $100 \mathrm{~s}$. The timescale of $100 \mathrm{~s}$ is based on estimate of the travel time on the neighbourhood scale (i.e. horizontal travel distances $\ll$ $1 \mathrm{~km})$.

\subsection{Modal composition and initial size-resolved UFP distribution}

The initial size-resolved UFP distribution is based on the measurements of Dall'Osto et al. (2011) and reproduced in Fig. S1. This ultrafine size distribution represents the typical street canyon bimodal size distribution found next to a traffic site, e.g. next to Marylebone Road in London (UK). The distribution has a well-defined nucleation mode with a peak number concentration at $D_{\mathrm{pg}, \mathrm{nuc}} \sim 23-24 \mathrm{~nm}$. The Aitken mode appears as a shoulder attached to the nucleation mode with a peak number concentration found at $D_{\mathrm{pg}, \text { aim }}$ between 50 and $60 \mathrm{~nm}$.

The initial UFP size-resolved composition is represented by modal compositions in the range from $\mathrm{C}_{16} \mathrm{H}_{34}$ to $\mathrm{C}_{32} \mathrm{H}_{66}$, as detailed above, and a standard deviation $\sigma$ from 1 to 5 . A non-volatile core is included in the UFPs. While studies broadly agree on the existence of a non-volatile core in the Aitken mode (Biswas et al., 2007; Wehner et al., 2004; Ronkko et al., 2013), it is unclear if nucleation-mode particles contain some non-volatile material or if they are entirely composed of SVOCs. We tested the sensitivity to the existence of non-volatile material in the nucleation-mode particles by initialising with $1 \%, 5 \%$, or $10 \%$ by mass non-volatile material for each modal composition (see Supplement); results are discussed later in this paper. Simulations are performed by considering the initialised Aitken mode predominantly non-volatile and coated only with $10 \%$ volatile material. This is based on the observations made during the REPARTEE campaign (Harrison et al., 2012) that show a fairly stable Aitken mode between the street canyon and the neighbourhood. The initial size-resolved modal com- 


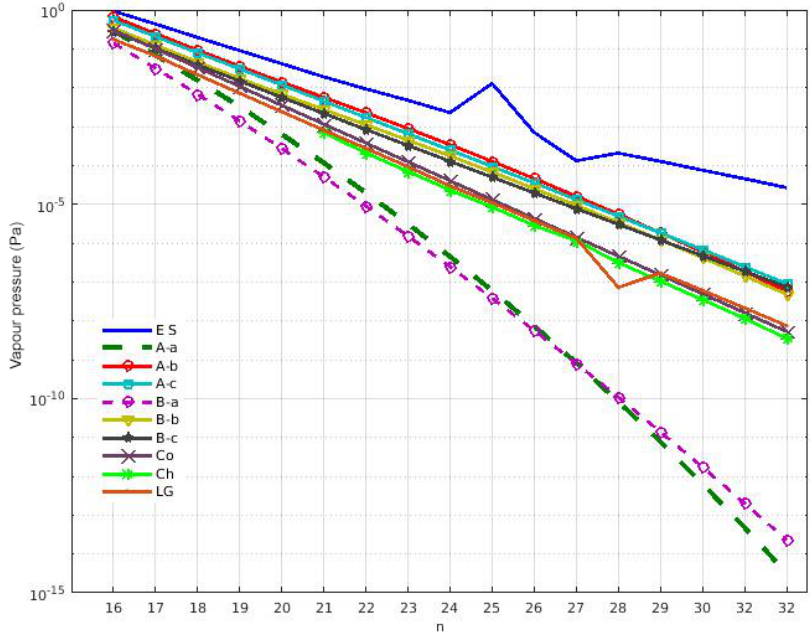

Figure 3. Vapour pressure data for selected $n$-alkanes $\mathrm{C}_{n} \mathrm{H}_{(2 n+2)}$ where $n=[16: 32]$ at $298 \mathrm{~K}$. Abbreviations in the legend indicate the source as follows: A and B refer to the vapour pressure data from Nannoolal et al. (2008) and Myrdal and Yalkowsky (1997), respectively; -a, -b, and -c refer to the boiling point of Joback and Reid (1987), Stein and Brown (1994), and Nannoolal et al. (2004), respectively; ES refers to the EPI Suite calculator (U.S. Environmental Protection Agency); Co refers to Compernolle et al. (2011); Ch refers to Chickos and Lipkind (2008); and LG refers to Lemmon and Goodwin (2000).

positions, composition standard deviations, and non-volatile core in the nucleation and Aitken modes are detailed in Tables S1-S4 in the Supplement. We also provide information on the input parameters of the log-normal UFP size distribution for the nucleation and Aitken modes.

\subsection{Saturation vapour pressures and gas-phase concentrations}

The driving force for condensation/evaporation is the difference between the partial pressure of each representative SVOC and its saturation vapour pressure (hereafter vapour pressure) over the ideal solution in the nucleation-mode condensed phase. Figure 3 shows vapour pressures above pure, flat, supercooled liquids for $n$-alkanes in the range from $\mathrm{C}_{16} \mathrm{H}_{34}$ to $\mathrm{C}_{32} \mathrm{H}_{66}$, following Chickos and Lipkind (2008), Compernolle et al. (2011), Lemmon and Goodwin (2000), the EPI Suite calculator (US EPA, 2017), and the UManSysProp tool (Topping et al., 2016). The UManSysProp tool provides vapour pressure data based on the work of Nannoolal et al. (2008) and Myrdal and Yalkowsky (1997) with the boiling points of Joback and Reid (1987), Stein and Brown (1994), and Nannoolal et al. (2004). There is a very substantial range of estimated vapour pressures for the same compounds in Fig. 3, especially for the high-molecularweight $n$-alkanes. The reported data agrees within 1 order of magnitude between $\mathrm{C}_{16} \mathrm{H}_{34}$ and $\mathrm{C}_{19} \mathrm{H}_{40}$, but discrepancies of much more than 1 order of magnitude are evident for the high-molecular-weight compounds. The vapour pressure ranges of $\mathrm{C}_{22} \mathrm{H}_{46}$ and $\mathrm{C}_{24} \mathrm{H}_{50}$ are between $\left[9.23 \times 10^{-3}\right.$ and $\left.8.94 \times 10^{-6} \mathrm{~Pa}\right]$ and $\left[2.26 \times 10^{-3}\right.$ and $\left.2.46 \times 10^{-7} \mathrm{~Pa}\right]$, respectively. An enormous difference in the vapour pressure for $\mathrm{C}_{32} \mathrm{H}_{66}$ (from $2.66 \times 10^{-5} \mathrm{~Pa}$ in EPI Suite, to $3.20 \times 10^{-15} \mathrm{~Pa}$ in Nannoolal et al., 2008 with the boiling point of Joback and Reid, 1987, referred to as A-a hereafter) is clearly seen in Fig. 3. EPI Suite (U.S. Environmental Protection Agency) provides the highest vapour pressures for all selected species in comparison with the rest of the data. Data from Nannoolal et al. (2008) and Myrdal-Yalkowsky (1997), which both use the boiling point of Joback and Reid (1987), provide similar results and present the lowest vapour pressures among the selected $n$-alkanes. For the purpose of our sensitivity study, the three following representative datasets are nominated as input: Myrdal-Yalkowsky (1997) with the boiling point of Nannoolal et al. (2004, referred to as B-c in Fig. 3 and hereafter); Compernolle et al. (2011), referred to as "Co" in the following; and A-a. Hereafter we use the legend abbreviations in Fig. 3 when referring to these selected vapour pressures, which are towards the upper, middle, and lower extents of the reported data. The vapour pressure from the EPI Suite calculator has been omitted from the analysis below to provide complementarity and no duplication of our previous study (Nikolova et al., 2016).

The gas-phase concentration in the box is initialised with measured gas-phase concentrations in the $\mathrm{C}_{16} \mathrm{H}_{34}$ to $\mathrm{C}_{32} \mathrm{H}_{66}$ range from a traffic site (Harrad et al., 2003) and reported in Table S6. For the hydroxyl $(\mathrm{OH})$ radical concentration $\sim 10^{6}$ molec $\mathrm{cm}^{-3}$, the timescale for atmospheric oxidation of $\mathrm{C}_{16} \mathrm{H}_{34}$ is about $10^{6} \mathrm{~s}$ (Atkinson and Arey, 2003). Therefore oxidation of SVOCs is neglected given the timescale in our study (100 s). The urban background gas-phase concentration is kept at zero. All model simulations are run at $298 \mathrm{~K}$; the effects of temperature on vapour pressure differences as a function of carbon number are discussed in the Supplement.

We performed a total of (17 modal compositions) $\times(5 \sigma-$ values $) \times(3$ non-volatile core amounts $) \times(3$ vapour pressures $)=765+(3$ mass accommodation coefficients $\times 3$ vapour pressure parameterisations) $=774$ model runs to explore the sensitivity of particle dynamics on the neighbourhood scale.

The Supplement contains information regarding the initial size distribution, modal composition in the nucleation and Aitken modes, and gas-phase concentrations. Accumulationmode aerosol (particles diameter $D_{\mathrm{p}}>100 \mathrm{~nm}$ ) is not considered in this study. Accumulation-mode particles have much smaller number concentrations than the nucleation and Aitken modes in polluted urban areas, and are influenced by ageing and transport over larger scales. 


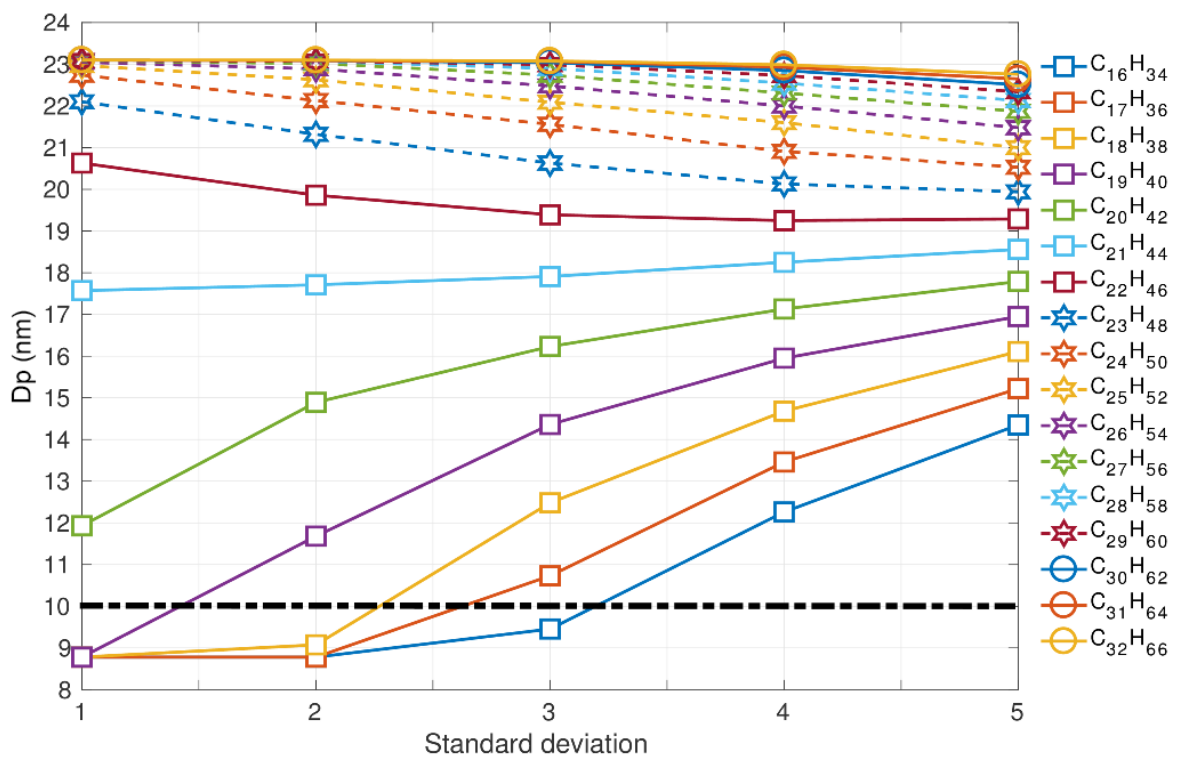

Figure 4. Nucleation-mode peak diameter $D_{\mathrm{p}}(\mathrm{nm})$ at $1 \mathrm{~s}$ of simulation depending on the modal composition and the composition standard deviation. The initial nucleation-mode peak diameter is at $23 \mathrm{~nm}$ (not shown on the figure). Vapour pressure data follows Compernolle et al. (2011).

\section{Results}

\subsection{Effect of composition on nucleation-mode peak diameter}

We consider first model runs in which the vapour pressure data follows the mid-range Co parameterisation (Compernolle et al., 2011), $\alpha=1$, and nucleation-mode particles are initialised with $1 \%$ non-volatile material. The nucleationmode peak diameter $D_{\mathrm{pg} \text {,nuc }}$ is evaluated at 1 and $100 \mathrm{~s}$ of model run-time in runs with varying modal composition and composition standard deviations. Figure 4 shows $D_{\text {pg,nuc }}$ ( $y$ axis) at $1 \mathrm{~s}$ simulation time, for each model run, plotted with respect to the modal composition and composition standard deviation, $\sigma$.

Figure 4 maps out the effect of nucleation-mode composition at this very early stage in the model simulation. For example, at $\sigma=1$ and initial mass distribution centred at $\mathrm{C}_{20} \mathrm{H}_{42}$ (the green solid line with square markers), the $D_{\mathrm{pg}, \text { nuc }}$ decreased from $23 \mathrm{~nm}$ (initial diameter at $t=0 \mathrm{~s}$ ) to $12 \mathrm{~nm}$ in $1 \mathrm{~s}$ due to evaporation of volatile material from the particles. At $\sigma=2, D_{\mathrm{pg}, \text { nuc }}=15 \mathrm{~nm}$, a somewhat larger diameter than for $\sigma=1$, due to the inclusion of material of lesser volatility in the particle composition and, hence, a decrease in evaporation overall. For modal compositions between $\mathrm{C}_{16} \mathrm{H}_{34}$ and $\mathrm{C}_{20} \mathrm{H}_{44}$, an increase in $\sigma$ leads to a pronounced deceleration in overall evaporation and, therefore, a much larger nucleation-mode peak diameter at $1 \mathrm{~s}$ simulation time. The opposite effect occurs for modal compositions of $\mathrm{C}_{22} \mathrm{H}_{46}$ and above, i.e. increasing $\sigma$ for a given modal com- position decreases $D_{\text {pg,nuc }}$ at $1 \mathrm{~s}$. This is due to the addition of quickly evaporating lower molecular weight $n$-alkanes.

For a modal composition of $\mathrm{C}_{21} \mathrm{H}_{44}$, increasing $\sigma$ makes almost no difference to the model outcome at $1 \mathrm{~s}$. In the following, we call the modal composition that shows insensitivity to $\sigma$ for a given model output time, the threshold modal composition. The threshold modal composition points to the composition compound that is in equilibrium between gas and particulate phases for the selected timescale. Lower carbon-number compositions than the threshold modal composition evaporate quicker and have therefore reached equilibrium with their respective gas concentrations on a much shorter timescale. The higher carbon-number compositions evaporate slowly and are out of equilibrium with their respective gas concentrations for the selected timescale.

The model output time of $1 \mathrm{~s}$ corresponds to the evaporation timescale of $\mathrm{C}_{21} \mathrm{H}_{44}$ under the current model setting, in analogy to the $e$-folding time for an exponentially decaying process. That is, at this time, a significant proportion (e.g. $1-\mathrm{e}^{-1} \sim 63 \%$ for one $e$-folding time, and $1-\mathrm{e}^{-2} \sim$ $86 \%$ for two $e$-folding times) of the initial mass has been evaporated. Furthermore, the timescales are much shorter for those lower than $\mathrm{C}_{21} \mathrm{H}_{44}$ carbon-number compositions (e.g. $\mathrm{C}_{20} \mathrm{H}_{42}, \mathrm{C}_{19} \mathrm{H}_{40} \ldots$ ) and much longer for those higher than $\mathrm{C}_{21} \mathrm{H}_{44}$ carbon-number compositions (e.g. $\mathrm{C}_{22} \mathrm{H}_{46}$, $\mathrm{C}_{23} \mathrm{H}_{48} \ldots$...

To continue the previous example of the modal composition of $\mathrm{C}_{20} \mathrm{H}_{42}$, the case with $\sigma=2$ includes not only less volatile materials (i.e. higher carbon-number SVOCs), but also an equal amount of more volatile materials (i.e. lower 
carbon-number SVOCs), as indicated by Fig. 2. One might suppose that the inclusion of the more volatile material would balance the effect of including less volatile materials. However, following our argument above, most of the lower carbon-number compounds including $\mathrm{C}_{20} \mathrm{H}_{42}$ will have evaporated before the given time of $1 \mathrm{~s}$ due to their shorter evaporation timescales with respect to $\mathrm{C}_{21} \mathrm{H}_{44}$. Thus, any material repartitioned from $\mathrm{C}_{20} \mathrm{H}_{42}$ to the lower carbonnumber compounds, in changing the model settings from to $\sigma=1$ to $\sigma=2$, will not alter the total amount of evaporation nor the shrinkage rate.

A second example is outlined in the following: for $\mathrm{C}_{22} \mathrm{H}_{46}$, any material reallocated from $\mathrm{C}_{22} \mathrm{H}_{46}$ to the higher carbonnumber compounds (due to changing the model setting from $\sigma=1$ to $\sigma=2$ ) will contribute negligibly to the shrinkage simply because the evaporation timescales for those higher carbon-number components are much longer than $1 \mathrm{~s}$. Conversely, the materials repartitioned from $\mathrm{C}_{22} \mathrm{H}_{46}$ to the lowercarbon compounds will contribute significantly to evaporation in the first $1 \mathrm{~s}$ of model run-time, causing the decreasing trend of the curve shown in Fig. 4.

One implication of this finding is that, if a timescale of $1 \mathrm{~s}$ is of interest, the aerosol dynamics of the system are dominated by the threshold modal composition of $\mathrm{C}_{21} \mathrm{H}_{44}$. Those lower carbon-number compositions evaporate in less than $1 \mathrm{~s}$ and are approximately in equilibrium with their respective gas concentrations in the environment. The higher carbonnumber compositions evaporate slowly and at $1 \mathrm{~s}$ only a small or a negligible proportion has been evaporated. A few compositions with the highest carbon numbers (e.g. $\mathrm{C}_{31} \mathrm{H}_{64}$, $\mathrm{C}_{32} \mathrm{H}_{66}$ ) have scarcely evaporated. Therefore these compositions are effectively non-volatile for these conditions.

Nucleation-mode particles have an initial non-volatile mass of $2.9 \mathrm{ng} \mathrm{m}^{-3}$. Modal compositions from $\mathrm{C}_{16} \mathrm{H}_{34}$ to $\mathrm{C}_{19} \mathrm{H}_{40}$ and $\sigma=1$ will lose all their volatile mass in $1 \mathrm{~s}$ (Table 1). The initial $D_{\mathrm{pg}, \mathrm{nuc}}$ decreases from 23 to $9 \mathrm{~nm}$ and no volatile material is present, i.e. particles are composed of non-volatile core only. Little or no change is simulated in terms of mass and diameter for modal composition $\mathrm{C}_{32} \mathrm{H}_{66}$.

At $100 \mathrm{~s}$, the evaporation of existing mass from the surface of the particles is also evident for higher molecularweight components (Table 1). The $D_{\mathrm{pg}, \text { nuc }}$ at $100 \mathrm{~s}$ is plotted in Fig. 5. The diameter has further decreased with a more pronounced drop for all $\sigma$ and modal compositions up to $\mathrm{C}_{25} \mathrm{H}_{52}$. Therefore, $\mathrm{C}_{25} \mathrm{H}_{52}$ is the threshold modal composition at this model output time.

The horizontal line drawn at $10 \mathrm{~nm}$ in Fig. 5 corresponds to evaporation approximating REPARTEE-like behaviour. At $\sigma=1$, modal compositions in the range from $\mathrm{C}_{16} \mathrm{H}_{34}$ to $\mathrm{C}_{23} \mathrm{H}_{48}$ - and vapour pressures and gas-phase partial pressures as detailed in the methodology - could plausibly explain a particle diameter decrease from 23 to $\sim 9 \mathrm{~nm}$. Such a narrow range of surrogate molecular compounds is incompatible with experimental observations such as Fig. 1. At $\sigma=2$ and $\sigma=3$, modal compositions from $\mathrm{C}_{16} \mathrm{H}_{34}$ up to

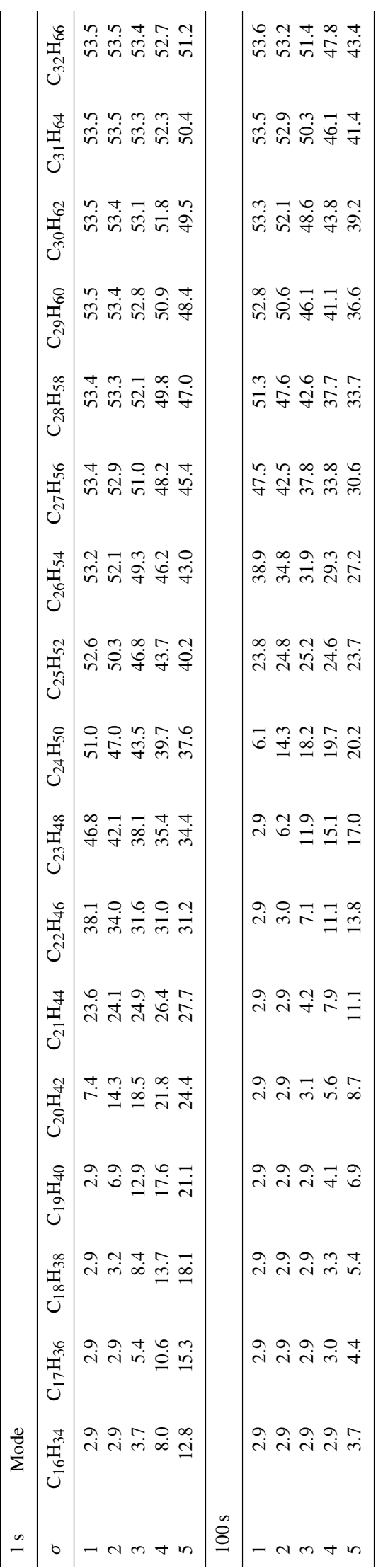

Atmos. Chem. Phys., 18, 17143-17155, 2018 


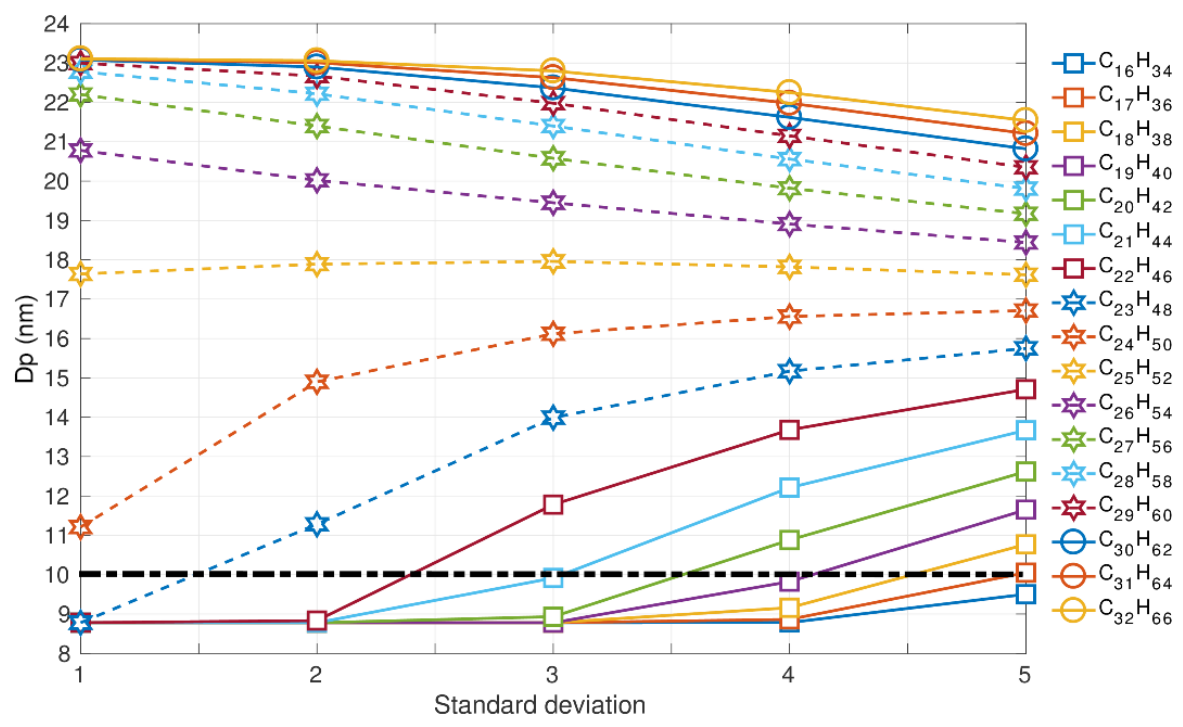

Figure 5. Nucleation-mode peak diameter $D_{\mathrm{p}}(\mathrm{nm})$ at $100 \mathrm{~s}$ of simulation depending on the modal composition and the composition standard deviation. The initial nucleation-mode peak diameter is at $23 \mathrm{~nm}$ (not shown on the figure).Vapour pressure data follows Compernolle et al. (2011).

$\mathrm{C}_{22} \mathrm{H}_{46}$ and $\mathrm{C}_{21} \mathrm{H}_{44}$, respectively, can plausibly approximate REPARTEE-like behaviour. At $\sigma=4$ and $\sigma=5$ modal compositions from $\mathrm{C}_{16} \mathrm{H}_{34}$ up to $\mathrm{C}_{19} \mathrm{H}_{40}$ and $\mathrm{C}_{17} \mathrm{H}_{36}$, respectively, plausibly simulate REPARTEE-like behaviour.

\subsection{Effect of vapour pressure on the nucleation-mode peak diameter}

We compare the simulated nucleation-mode peak diameter, $D_{\text {pg,nuc }}$, at $100 \mathrm{~s}$ using the vapour pressure parameterisations B-c, Co, and A-a (cf. Fig. 3). The nucleation-mode particles are initialised with $1 \%$ non-volatile material in these simulations and $\alpha=1$. The diameter change when using the Co vapour pressure was discussed in the previous section. The vapour pressure values in the Co data are intermediate between the B-c and A-a data. Hence, $D_{\mathrm{pg} \text {,nuc }}$ at $100 \mathrm{~s}$ using vapour pressure parameterisations A-a and B-c (see Supplement), as expected, shows the same general behaviour as for the vapour pressure parameterisation $\mathrm{Co}$, but with a marked change in the threshold modal composition. In order of decreasing vapour pressure (Fig. 3), the $100 \mathrm{~s}$ threshold modal composition value changes from $\mathrm{C}_{27} \mathrm{H}_{56}$ for the B-c parameterisation (Fig. S4), to $\mathrm{C}_{25} \mathrm{H}_{52}$ for Co (Fig. 5), to $\mathrm{C}_{22} \mathrm{H}_{46}$ for A-a (Fig. S5). We restrict ourselves to integer values of the threshold modal composition to maintain a straightforward connection back to the homologous chemical series in Fig. 1, although there is nothing in principle to prevent us from attributing real number values to the threshold modal composition.

There is no composition with $\sigma=4$ or $\sigma=5$, at the lower volatility A-a vapour pressure parameterisation, which produces REPARTEE-like behaviour; i.e. the decrease of the
Table 2. Modal composition ranges and composition standard deviations, $\sigma$, producing model results that approximate REPARTEElike behaviour (see main text), for different vapour pressure parameterisations. Initial non-volatile core in the nucleation mode is set to $1 \%$.

\begin{tabular}{llll}
\hline $\begin{array}{l}\text { Vapour pressure } \\
\sigma\end{array}$ & B-c & Co & A-a \\
\hline 1 & & & \\
2 & $\leq \mathrm{C}_{25} \mathrm{H}_{52}$ & $\leq \mathrm{C}_{23} \mathrm{H}_{48}$ & $\leq \mathrm{C}_{20} \mathrm{H}_{42}$ \\
3 & $\leq \mathrm{C}_{24} \mathrm{H}_{50}$ & $\leq \mathrm{C}_{22} \mathrm{H}_{46}$ & $\leq \mathrm{C}_{19} \mathrm{H}_{40}$ \\
4 & $\leq \mathrm{C}_{23} \mathrm{H}_{48}$ & $\leq \mathrm{C}_{21} \mathrm{H}_{44}$ & $\leq \mathrm{C}_{17} \mathrm{H}_{36}$ \\
5 & $\leq \mathrm{C}_{21} \mathrm{H}_{44}$ & $\leq \mathrm{C}_{19} \mathrm{H}_{40}$ & - \\
& $\leq \mathrm{C}_{20} \mathrm{H}_{42}$ & $\leq \mathrm{C}_{17} \mathrm{H}_{36}$ & - \\
\hline
\end{tabular}

nucleation-mode peak diameter from 23 to $10 \mathrm{~nm}$ or below. At $\sigma=5$, the nucleation-mode particles can lose a maximum of $\sim 9 \mathrm{~nm}$ of their initial diameter for modal composition $\mathrm{C}_{16} \mathrm{H}_{34}$ (please refer to Fig. S5). Little or no change in mode diameter is simulated for modal compositions between $\mathrm{C}_{24} \mathrm{H}_{50}$ and $\mathrm{C}_{32} \mathrm{H}_{66}$ and $\sigma=1$, indicating that these combinations of composition and vapour pressure parameterisation are essentially non-volatile for the $100 \mathrm{~s}$ simulation time. Modal compositions $\mathrm{C}_{20} \mathrm{H}_{42}(\sigma=1), \mathrm{C}_{19} \mathrm{H}_{40}(\sigma=2)$, and $\mathrm{C}_{17} \mathrm{H}_{36}(\sigma=3)$ can produce REPARTEE-like aerosol dynamics.

Vapour pressure parameterisation B-c has the highest vapour pressure for all compounds in comparison with Co and A-a. Hence, particles in the nucleation mode are subject to a more pronounced evaporation, even for modal compositions $\mathrm{C}_{28} \mathrm{H}_{58}$ to $\mathrm{C}_{32} \mathrm{H}_{66}$. Nonetheless, only modal compositions $\mathrm{C}_{25} \mathrm{H}_{52}(\sigma=1), \mathrm{C}_{24} \mathrm{H}_{50}(\sigma=2), \mathrm{C}_{23} \mathrm{H}_{48}(\sigma=3)$, 


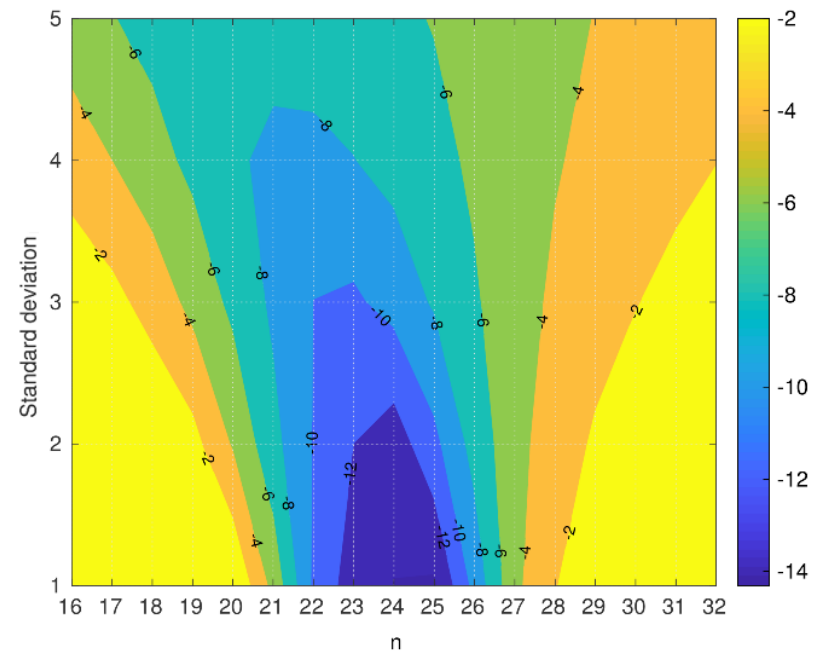

Figure 6. $D_{\text {pg,nuc }}$ difference between the nucleation-mode peak diameter (nm) when using B-c vapour pressure and the nucleationmode peak diameter when using A-a vapour pressure for modal compositions $\mathrm{C}_{n} \mathrm{H}_{(2 n+2)}$, where $n=[16: 32]$.

$\mathrm{C}_{21} \mathrm{H}_{44}(\sigma=4)$, and $\mathrm{C}_{20} \mathrm{H}_{42}(\sigma=5)$ are able to produce the REPARTEE-like behaviour. Table 2 provides details on the modal compositions and composition standard deviations that approximate the REPARTEE-like aerosol dynamics for $\mathrm{B}-\mathrm{c}, \mathrm{Co}$, and A-a vapour pressure parameterisations.

The difference in $100 \mathrm{~s} D_{\mathrm{pg}, \text { nuc }}$ between the highest vapour pressure (B-c) and the lowest vapour pressure (A-a) for all values of $\sigma$, is shown in Fig. 6. The largest differences (10$14 \mathrm{~nm}$ ) between the $D_{\text {pg,nuc }}$ occur for modal compositions between $\mathrm{C}_{22} \mathrm{H}_{46}$ and $\mathrm{C}_{24} \mathrm{H}_{50}$ and $\sigma=1,2$, and 3. For a model run-time of $100 \mathrm{~s}$, the variability of the UFP shrinkage due to the uncertainty of vapour pressure data is highest for the compositions between $\mathrm{C}_{22} \mathrm{H}_{46}$ and $\mathrm{C}_{24} \mathrm{H}_{50}$. From Fig. 3, we see that the uncertainty of the vapour pressure data increases monotonically with carbon number and is highest for $\mathrm{C}_{32} \mathrm{H}_{66}$. However, the large vapour-pressure uncertainties for high-carbon compositions do not exert a significant impact on the model results for this scenario. Thus, we conclude that the accuracies of vapour pressure values for very high or very low carbon-number compositions are not important for neighbourhood-scale aerosol dynamics.

\subsection{Effect of non-volatile core on the nucleation-mode peak particle diameter}

To consider how the fraction of non-volatile core interacts with the composition of SVOCs and the vapour pressure parameterisations, we define a " $100 \mathrm{~s}$ effective non-volatile core": the nucleation-mode peak diameter at $100 \mathrm{~s}$ of evaporation. Figure 7 shows the results for three non-volatile fractions (initial $1 \%, 5 \%$, and $10 \%$ based on mass) and vapour pressures A-a, B-c, and Co (cf. Fig. 3) for a modal compo-

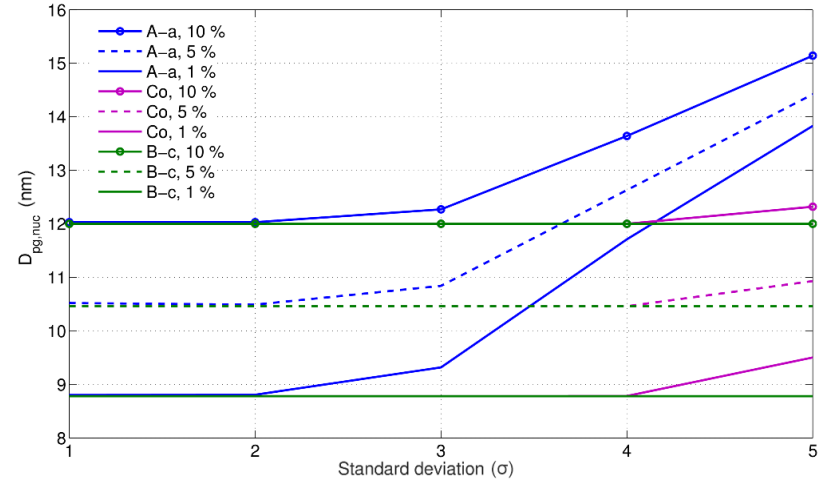

Figure 7. Nucleation-mode peak diameter $D_{\mathrm{p}}(\mathrm{nm})$ at $100 \mathrm{~s}$ : the "100 s effective non-volatile core" for the nucleation mode. Results are shown at $1 \%, 5 \%$, and $10 \%$ initial non- volatile material in the nucleation-mode particles, modal composition $\mathrm{C}_{16} \mathrm{H}_{34}$, and for various composition standard deviations.

sition of $\mathrm{C}_{16} \mathrm{H}_{34}$. Results for the remaining modal compositions are not plotted here because using modal composition $\mathrm{C}_{16} \mathrm{H}_{34}$ and an evaporation time of 100 s gives the maximum reduction of the nucleation-mode peak diameter for all $\sigma$ in our model runs. However, we show the results for modal compositions $\mathrm{C}_{24} \mathrm{H}_{50}$ and $\mathrm{C}_{32} \mathrm{H}_{66}$ for completeness in the Supplement (Fig. S7).

Because the mass-size distribution is held constant for each model initialisation (see Supplement), an increase of the non-volatile material in the nucleation mode leads to a decrease in the total amount of $n$-alkane SVOCs available for evaporation, and subsequently leads to an increase in the nucleation-mode "dry" (i.e. non-volatile core only) diameter from $\sim 9$ to $\sim 12 \mathrm{~nm}$. For the lowest volatility parameterisation (A-a), only the lightest surrogate compounds near $\mathrm{C}_{16} \mathrm{H}_{34}$ are sufficiently volatile over the timescale of the model run to drive the evaporation of nucleation-mode particles. As $\sigma$ increases, an increasing number of lower volatility components are added into the particle composition, causing the $100 \mathrm{~s}$ effective non-volatile core to increase.

Considering REPARTEE-like behaviour, i.e. shrinkage of the nucleation-mode diameter to ca. $10 \mathrm{~nm}$, initial nonvolatile core fractions of $5 \%$ or greater do not reproduce the observed behaviour.

\subsection{Effect of a mass accommodation coefficient less than unity}

The effect of reducing the value of the mass accommodation coefficient, from the default value of unity, is shown in Fig. 8 as a function of the modal standard deviation and vapour pressure, for a modal composition of $\mathrm{C}_{16} \mathrm{H}_{34}$. Considering our default Co vapour pressure parameterisation first, using $\alpha=1$ results in rapid evaporation and a small $D_{\mathrm{pg} \text {,nuc }}$ for $1 \leq \sigma<5$. As discussed in Sect. 3.1, such combinations of modal composition and vapour pressure parameterisation 


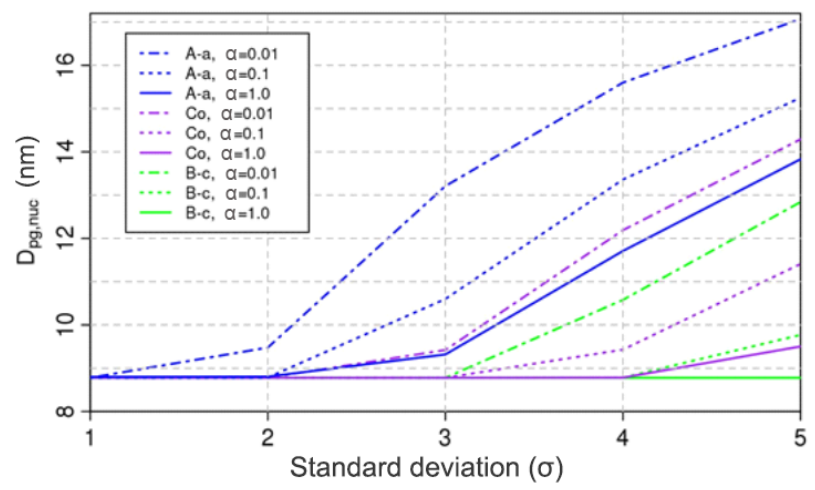

Figure 8. Nucleation-mode peak diameter $D_{\mathrm{p}}(\mathrm{nm})$ at $100 \mathrm{~s}$ of simulation depending on the mass accommodation coefficient, the vapour pressure parameterisation, and the composition standard deviation. The initial nucleation-mode peak diameter is at $23 \mathrm{~nm}$ (not shown in the figure). Results are shown for $1 \%$ initial nonvolatile material in the nucleation-mode particles, modal composition $\mathrm{C}_{16} \mathrm{H}_{34}$, and for various composition standard deviations. The vapour pressure parameterisations are labelled as in Fig. 3.

produce a very volatile nucleation-mode aerosol that evaporates "to dryness" over the course of the model run. Decreasing the value of the mass accommodation coefficient decreases the effective volatility of the model runs with Co vapour pressure (Fig. 8), leading to larger values of $D_{\mathrm{pg}, \mathrm{nuc}}$. Similarly, end-of-run values of $D_{\mathrm{pg} \text {,nuc }}$ increase with decreasing values of $\alpha$ for the A-a and B-c vapour pressure parameterisations. The overall effect is such that model runs using the higher volatility B-c parameterisation and $\alpha=0.1$ match results using the Co vapour pressures and $\alpha=1$. Similarly, model runs using the lower volatility A-a parameterisation and $\alpha=1$ match results using the Co vapour pressures and $\alpha=0.01$. Determining which combination of vapour pressure and mass accommodation is more realistic requires further laboratory experiments to constrain these properties.

\section{Discussion and Conclusions}

The purpose of this study was to evaluate the importance of particle composition and saturation vapour pressure on the evolution of urban ultrafine diesel particles on the neighbourhood scale $(\ll 1 \mathrm{~km})$ by means of numerical simulations. We presented the effect of evaporation on the size-resolved ultrafine particles and looked at the evolution of the nucleationmode peak diameter $\left(D_{\mathrm{pg}, \mathrm{nuc}}\right)$ depending on particle SVOC composition, vapour pressure, fraction of non-volatile core in the particles, and the value of the mass accommodation coefficient. We used laboratory measurements of the sizeresolved composition of UFPs as an additional strong constraint on the plausibility of model parameter sets. We identified a group of surrogate $n$-alkane compounds in the range from $\mathrm{C}_{16} \mathrm{H}_{34}$ to $\mathrm{C}_{32} \mathrm{H}_{66}$ that could explain REPARTEE-like aerosol dynamics measured in London (Dall'Osto et al., 2011): i.e. a final nucleation-mode peak diameter at $10 \mathrm{~nm}$ or below when particles were subject to evaporation on a timescale of $100 \mathrm{~s}$. Table 2 highlights the set of parameters in terms of vapour pressure and modal compositions that produce such REPARTEE-like behaviour.

Table 2 also presents the sets of model parameters consistent with diameter reduction due to evaporation. However, the question regarding the extent to which these results are realistic and relevant for the real-world atmosphere remains. The standard deviation $\sigma=1$ for all vapour pressures significantly narrows the contribution from the $n$-alkanes $([\max (16$, $j-2), \min (32, j+2)]$ for modal composition $j)$, present in the initial composition of the nucleation-mode particles. At $\sigma=2$, the main contributing compounds involved in particle composition are the modal composition $j$ and the surrogate molecules $[\max (16, j-4), \min (32, j+4)]$. This means that for the given vapour pressure parameterisation, A-a, and modal composition $\mathrm{C}_{19} \mathrm{H}_{40}$, the compounds found in the particles would be between $\mathrm{C}_{15} \mathrm{H}_{32}$ and $\mathrm{C}_{23} \mathrm{H}_{48}$. However, $\mathrm{C}_{16} \mathrm{H}_{34}$ is the lower limit of surrogate compounds in the model, so the Gaussian distribution of the composition is truncated at the low carbon-number end in this case. At $\sigma=3$, the contributing compounds found in the particles are the surrogate molecules in the range $[\max (16, j-7)$, $\min (32, j+7)]$. For a modal composition $\mathrm{C}_{17} \mathrm{H}_{36}$ and $\mathrm{A}$ a vapour pressure, the range of participating compounds is $\mathrm{C}_{16} \mathrm{H}_{34}-\mathrm{C}_{24} \mathrm{H}_{50}$, similar to the case of $\sigma=2$. At $\sigma=4$ and 5 , the majority of the surrogate molecules in our range of $n$-alkanes participate in the composition of particles; thus, a reasonable range is provided over the contribution from diesel fuel and engine lubricating oil. The range at $\sigma=3$ could be considered as a transition range, while examples at $\sigma=2$ would have compositions that are rather more limited than available measurements in the Aitken mode (e.g. Fig. 1), with a focus on the contribution from the engine lubricating oil. Overall, narrow compositions would imply a strong gradient of SVOCs across the nucleation and Aitken modes whereas broad compositions imply that SVOCs are more or less evenly distributed across the ultrafine size range.

Table 3 shows an additionally constrained range of modal compositions consistent with what we know from field and laboratory measurements combined. The lowest vapour pressure parameterisations (A-a and the very similar B-a, see Fig. 3) are less likely, at any modal composition standard deviation $(\sigma)$ and mass accommodation coefficient, to represent the laboratory and field observations together. The results reported in Alam et al. (2016) and in Fig. 1 show that diesel ultrafine particle emissions are composed of a wealth of SVOCs that are mainly identified as straight and branched alkanes in the range from $\mathrm{C}_{11}$ to $\mathrm{C}_{33}$, cycloalkanes $\left(\mathrm{C}_{11}-\mathrm{C}_{25}\right)$, polycyclic aromatic hydrocarbons, various cyclic aromatics, alkyl benzenes and decalins. They report emitted particulate size fractionated concentrations of $n$ alkanes (cf. Fig. S2) and point out that particles in the 5- 
Table 3. Modal composition range and composition standard deviations, $\sigma$, producing more realistic results that approximate REPARTEE-like behaviour. The vapour pressure parameterisations follow Myrdal and Yalkowski (1997; B-c in Fig. 3), Compernolle et al. (2011; Co in Fig. 3), and Nannoolal 2008; A-a in Fig. 3). Column "cn" indicates the carbon number of compounds $n$ in the modal composition with a contribution bigger than $1 \%$.

\begin{tabular}{llllr}
\hline $\begin{array}{l}\text { Vapour pressure } \\
\sigma\end{array}$ & B-c & Co & $\begin{array}{l}\text { A-a } \\
\text { cn } \\
\pm\end{array}$ \\
\hline 1 & - & - & - & 2 \\
2 & $\mathrm{C}_{21} \mathrm{H}_{44}-\mathrm{C}_{24} \mathrm{H}_{50}$ & $\mathrm{C}_{21} \mathrm{H}_{44}-\mathrm{C}_{22} \mathrm{H}_{46}$ & - & 4 \\
3 & $\mathrm{C}_{19} \mathrm{H}_{40}-\mathrm{C}_{23} \mathrm{H}_{48}$ & $\mathrm{C}_{19} \mathrm{H}_{40}-\mathrm{C}_{21} \mathrm{H}_{44}$ & - & 7 \\
4 & $\leq \mathrm{C}_{21} \mathrm{H}_{44}$ & $\leq \mathrm{C}_{19} \mathrm{H}_{40}$ & - & 9 \\
5 & $\leq \mathrm{C}_{20} \mathrm{H}_{42}$ & $\leq \mathrm{C}_{17} \mathrm{H}_{36}$ & - & 11 \\
\hline
\end{tabular}

$100 \mathrm{~nm}$ diameter range mainly consist of high-molecularweight SVOCs $\left(>\mathrm{C}_{24} \mathrm{H}_{50}\right)$ associated with engine lubricating oil. The work of Robinson et al. (2007), Grishop et al. (2009), and May et al. (2013) also point to a Gaussiantype distribution of the exhaust particle composition centred at a SVOC, which has a wide standard deviation.

Vapour pressure parameterisations used in this study and plotted in Fig. 3, are one of the crucial input parameters in assessing the rate at which condensation/evaporation can occur, although they are poorly constrained. We introduced a new concept of threshold modal composition, i.e. a modal composition that is not sensitive to $\sigma$ for a given model output time. In an order of decreasing vapour pressure (Fig. 3) and timescale of $100 \mathrm{~s}$, the threshold modal composition value changes from $\mathrm{C}_{27} \mathrm{H}_{56}$ for the B-c parameterisation (Fig. S4), to $\mathrm{C}_{25} \mathrm{H}_{52}$ for $\mathrm{Co}$ (Fig. 5), to $\mathrm{C}_{22} \mathrm{H}_{46}$ for A-a (Fig. S5). Overall, the largest differences $(\sim 14 \mathrm{~nm})$ in the $100 \mathrm{~s} D_{\mathrm{pg} \text {,nuc }}$ occur between the highest (B-c) and the lowest (A-a) vapour pressure parameterisations for modal compositions between $\mathrm{C}_{22} \mathrm{H}_{46}$ and $\mathrm{C}_{24} \mathrm{H}_{50}$ and a composition standard deviation from 1 to 3 . The vapour pressures of components in this range are therefore critical for the modelling of nucleationmode aerosol dynamics on the neighbourhood scale. For components with a volatility less than that of the $\mathrm{C}_{22} \mathrm{H}_{46}$ surrogate compound used here, all available vapour pressure parameterisations render these compounds volatile over the $100 \mathrm{~s}$ timescale. These components will equilibrate with the gas phase on these short timescales. Components with volatility lower than that of the $\mathrm{C}_{24} \mathrm{H}_{50}$ surrogate are effectively non-volatile over this timescale for all vapour pressure parameterisations, and will consequently remain condensed and out of equilibrium with the gas phase on these timescales.

The other variable which will influence evaporation rate is the concentration of vapour surrounding the particles. In this work, measured roadside vapour concentrations reported by Harrad et al. (2003) are used (see also Nikolova et al., 2016). These represent an upper estimate of gas-phase partial pressures away from the roadside. Mixing of cleaner urban back- ground air into the simulated air parcel would lower partial pressures and increase evaporation rates.

The $100 \mathrm{~s}$ effective non-volatile core (the nucleation-mode peak diameter at $100 \mathrm{~s}$ of evaporation) increased from $\sim 9$ to $\sim 12 \mathrm{~nm}$. This was attributed to the decrease in the total amount of $n$-alkane surrogate compounds present for evaporation. As composition standard deviation $\sigma$ increased, an increasing number of lower volatility components added into the particle composition caused the $100 \mathrm{~s}$ effective nonvolatile core to further increase. Considering REPARTEElike behaviour, i.e. shrinkage of the nucleation-mode diameter to ca. $10 \mathrm{~nm}$, an initial non-volatile core of $5 \%$ by mass or greater was not capable of reproducing the observed behaviour in the atmosphere. Because the higher molecularweight (lower volatility) surrogate molecules in the model are essentially non-volatile over the modelling timescale, the nucleation-mode dynamics due to SVOCs are confounded with the dynamics due to the size of any non-volatile core present in the particles.

We find that the model results for a given vapour-pressure parameterisation vary markedly depending on the choice of the mass accommodation coefficient value, $\alpha$. Higher volatility vapour-pressure parameterisations with low values of $\alpha$ give model results similar to runs with less volatile vapourpressure parameterisations and higher values of $\alpha$. Such equifinality in model runs awaits further laboratory work to disambiguate.

Results (Fig. 7) suggest that urban nucleation-mode particles should be predominantly volatile in order to produce REPARTEE-like behaviour. In these numerical experiments, the nature of the non-volatile core need not be specified. This core could be composed of one or more low vapour pressure compounds, not affected by condensation/evaporation on the timescale of the model and measurements. Conversely, as discussed in Nikolova et al. (2016), a non-volatile core could be composed mainly of carbon and possibly some contribution from metal oxides and sulphates. This difference in composition could be relevant to effects on human health. $\mathrm{Li}$ et al. (2010) show that diesel truck emissions during idle induce a high level of oxidative stress in human aortic endothelial cells, due to the type of metals and trace metals found in the exhaust; furthermore Xia et al. (2015) argue that trafficrelated UFPs act to promote airway inflammation due to the rich content of organic species. The relative importance of these particles in affecting human health merits further investigations.

Laboratory exhaust diesel UFP measurements are highly dependent on the sampling methods. Measurements of the UFP composition from a diesel-fuelled engine are still at an early stage; therefore, more effort should be put into developing sampling protocols that target the composition of the nucleation- and Aitken-mode particles in a realistic manner. There are no robust UFP chemical composition measurements at street scale and therefore such measurements devoted to address in detail the composition of the traffic emit- 
ted UFP in the atmosphere are urgently needed. Saturation vapour pressure is another source of large uncertainties; our study lays out a strategy to determine which vapour pressures are most significant in a given modelling scenario.

Data availability. Please see Nikolova et al. (2018; https://doi.org/10.25500/eData.bham.00000275) for model code and output.

Supplement. The supplement related to this article is available online at: https://doi.org/10.5194/acp-18-17143-2018-supplement.

Author contributions. The study was conceived by ARM, XC, and RMH; IN and JZ wrote code and ran model simulations; MSA and SZR provided laboratory data to compare with the model results; $\mathrm{RMH}$ and MSA provided field data to compare with the model results; all authors contributed to writing the paper.

Competing interests. The authors declare that they have no conflict of interest.

Acknowledgements. This work is part of the FASTER project, ERC-2012-AdG, proposal no. 320821 sponsored by the European Research Council (ERC). A. Rob MacKenzie, Jian Zhong, and Mohammed Salim Alam gratefully acknowledge additional support from the UK Natural Environment Research Council (NERC grant nos. NE/N003195/1 and NE/P016499/1).

Edited by: Alma Hodzic

Reviewed by: three anonymous referees

\section{References}

Alam, M. S, Rezaei, S. Z., Stark, C. P., Liang, Z., Xu, H. M., and Harrison, R. M.: The characterisation of diesel exhaust particles - composition, size distribution and partitioning, Faraday Discuss., 189, 69-84, 2016.

Alam, M. S., Zeraati-Rezaei, S., Liang, Z., Stark, C., Xu, H., MacKenzie, A. R., and Harrison, R. M.: Mapping and quantifying isomer sets of hydrocarbons $\left(\geq \mathrm{C}_{12}\right)$ in diesel exhaust, lubricating oil and diesel fuel samples using GC $\times$ GC-ToF-MS, Atmos. Meas. Tech., 11, 3047-3058, https://doi.org/10.5194/amt11-3047-2018, 2018.

Allen, L. R., Donahue, N. M., Shrivastava, M. K., Weitkamp, E. A., Sage, A. M., Grieshop, A. P., Lane, T. E., Pierce, J. R., and Pandis, S. N.: Rethinking organic aerosols: semivolatile emissions and photochemical aging, Science, 315, 1259-1262, 2007.

Atkinson, R. W., Fuller, G. W., Anderson, H. R., Harrison, R. M., and Armstrong, B.: Urban ambient particle metrics and health: a time-series analysis, Epidemiology, 21, 501-511, 2010.
Biswas, S., Ntziachristos, L., Moore, K. F., and Sioutas, C.: Particle volatility in the vicinity of a freeway with heavy-duty diesel traffic, Atmos. Environ., 41, 3479-3493, 2007.

Chan, A. W. H., Isaacman, G., Wilson, K. R., Worton, D. R., Ruehl, C. R., Nah, T., Gentner, D. R., Dallmann, T. R., Kirchstetter, T. W., Harley, R. A., Gilman, J. B., Kuster, W. C., de Gouw, J. A., Offenberg, J. H., Kleindienst, T. E., Lin, Y. H., Rubitschun, C. L., Surratt, J. D., Hayes, P. L., Jimenez, J. L., and Goldstein, A. H.: Detailed chemical characterization of unresolved complex mixtures in atmospheric organics:insights into emission sources, atmospheric processing, and secondary organic aerosol formation, J. Geophys. Res.-Atmos., 118, 6783-6796, 2013.

Chickos, J. and Lipkind, D.: Hypothetical thermodynamic properties: vapour pressures and vaporization enthalpies of the even $n$ alkanes from $\mathrm{C}_{78}$ to $\mathrm{C}_{92}$ at $T=298.15 \mathrm{~K}$ by correlation-gas chromatography, J. Chem. Eng. Data, 53, 2432-2440, 2008.

Compernolle, S., Ceulemans, K., and Müller, J.-F.: EVAPORATION: a new vapour pressure estimation methodfor organic molecules including non-additivity and intramolecular interactions, Atmos. Chem. Phys., 11, 9431-9450, https://doi.org/10.5194/acp-11-9431-2011, 2011.

Dall'Osto, M., Thorpe, A., Beddows, D. C. S., Harrison, R. M., Barlow, J. F., Dunbar, T., Williams, P. I., and Coe, H.: Remarkable dynamics of nanoparticles in the urban atmosphere, Atmos. Chem. Phys., 11, 6623-6637, https://doi.org/10.5194/acp11-6623-2011, 2011.

Donahue, N. M., Robinson, A. L., Stanier, C. O., and Pandis, S. N.: Coupled partitioning, dilution, and chemical aging of semivolatile organics, Environ. Sci. Technol., 40, 2635-2643, 2006.

Grieshop, A. P., Miracolo, M. A., Donahue, N. M., and Robinson, A. L.: Constraining the Volatility Distribution and Gas-Particle Partitioning of Combustion Aerosols Using Isothermal Dilution and Thermodenuder Measurements, Environ. Sci. Technol., 43 4750-4756, https://doi.org/10.1021/es8032378, 2009.

Harrad, S., Hassoun, S., Callen Romero, M. S., and Harrison, R. M.: Characterisation and source attribution of the semi-volatile organic content of atmospheric particles and associate vapour phase in Birmingham, UK, Atmos. Environ., 37, 4985-4991, 2003.

Harrison, R. M., Beddows, D. S., and Dall'Osto, M.: PMF analysis of wide-range particle size spectra collected on a major highway, Environ. Sci. Technol., 45, 5522-5528, 2011.

Harrison, R. M., Dall'Osto, M., Beddows, D. C. S., Thorpe, A. J., Bloss, W. J., Allan, J. D., Coe, H., Dorsey, J. R., Gallagher, M., Martin, C., Whitehead, J., Williams, P. I., Jones, R. L., Langridge, J. M., Benton, A. K., Ball, S. M., Langford, B., Hewitt, C. N., Davison, B., Martin, D., Petersson, K. F., Henshaw, S. J., White, I. R., Shallcross, D. E., Barlow, J. F., Dunbar, T., Davies, F., Nemitz, E., Phillips, G. J., Helfter, C., Di Marco, C. F., and Smith, S.: Atmospheric chemistry and physics in the atmosphere of a developed megacity (London): an overview of the REPARTEE experiment and its conclusions, Atmos. Chem. Phys., 12, 3065-3114, https://doi.org/10.5194/acp-12-3065-2012, 2012.

Harrison, R. M., Jones, A. M., Beddows, D. C. S., Dall'Osto, M., and Nikolova, I.: Evaporation of traffic-generated nanoparticles during advection from source, Atmos. Environ., 125, 1-7, 2016. 
Jacobson, M. Z.: Development and application of a new air pollution modeling system, 2. Aerosol module structure and design, Atmos. Environ., 31, 131-144, 1997.

Jacobson, M. Z., Kittelson, D. B., and Watts, W. F.: Enhanced coagulation due to evaporation and its effect on nanoparticle evolution, Environ. Sci. Technol., 39, 9486-9492, 2005.

Joback, K. and Reid, R.: Estimation of Pure-component properties from group-contributions, Chem. Eng. Commun., 57, 233-243, 1987.

Julin, J., Winkler, P. M., Donahue, N. M., Wagner, P. E., and Riipinen, I.: Nera-unity mass accomodation coefficient of organic molecules of varying structure, Environ. Sci. Technol., 48, 12083-12089, 2014.

Karl, M., Kukkonen, J., Keuken, M. P., Lützenkirchen, S., Pirjola, L., and Hussein, T.: Modeling and measurements of urban aerosol processes on the neighborhood scale in Rotterdam, Oslo and Helsinki, Atmos. Chem. Phys., 16, 4817-4835, https://doi.org/10.5194/acp-16-4817-2016, 2016.

Karnezi, E., Riipinen, I., and Pandis, S. N.: Measuring the atmospheric organic aerosol volatility distribution: a theoretical analysis, Atmos. Meas. Tech., 7, 2953-2965, https://doi.org/10.5194/amt-7-2953-2014, 2014.

Kumar, P., Morawska, L., Birmili, W., Paasonen, P., Hu, M., Kulmala, M., Harrison, R. M., Norford, L., and Britter, R.: Ultrafine particles in cities, Environ. Intl., 66, 1-10, 2014.

Lemmon, E. W. and Goodwin, A. R. H.: Critical properties and vapour pressure equation for alkanes $\mathrm{C}_{n} \mathrm{H}_{2 n+2}$ : normal alkanes with $n \leq 36$ and isomers for $n=4$ through $n=9$, J. Phys. Chem. Ref. Data, 29, 1-39, 2000.

Li, R., Ning, Z., Majumdar, R., Cui, J., Takabe, W., Jen, N., Sioutas, C. and Hsiai, T.: Ultrafine particles from diesel vehicle emissions at different driving cycles induce differential vascular pro-inflamatory responses: implications of chemical components and NF-kB signaling, Part. Fibre Toxicol., 7, 6, https://doi.org/10.1186/1743-8977-7-6, 2010.

May, A. A., Presto, A. A., Hennigan, C. J., Nguyen, N. T., Gordon, T. D., and Robinson, A. L.: Gas-particle partitioning of primary organic aerosol emissions: (2) Diesel vehicles, Environ. Sci. Technol., 47, 8288-8296, 2013.

Myrdal, P. B. and Yalkowsky, S. H.: Estimating pure component vapor pressures of complex organic molecules, Ind. Eng. Chem. Res., 36, 2494-2499, 1997.

Nannoolal, Y., Rarey, J., Ramjugernath, D. and Cordes, W.: Estimation of pure component properties: Part 1. Estimation of the normal boiling point of non-electrolyte organic compounds via group contributions and group interactions, Fluid Phase Equilibr., 226, 45-63, 2004.

Nannoolal, Y., Rarey, J., and Ramjugernath, D.: Estimation of pure component properties: Part 3. Estimation of the vapor pressure of non-electrolyte organic compounds via group contributions and group interactions, Fluid Phase Equilibr., 269, 117-133, 2008.
Nikolova, I., Janssen S., Vos, P., Vrancken, K., Mishra, V., and Berghmans, P.: Dispersion modelling of traffic induced ultrafine particles in a street canyon in Antwerp, Belgium and comparison with observations, Sci. Total Environ., 412-413, 336-343, 2011.

Nikolova, I., MacKenzie, A. R., Cai, X., Alam, M. S., and Harrison, R. M.: Modelling component evaporation and coposition change of traffic-induced ultrafine particles during travel from street canyon to urban background, Faraday Discuss., 189, 529 546, 2016.

Nikolova, I., Zhong, J., Harrison, R. M., Alam, M. S., Zeraati Rezaei, S., Cai, X., and Mackenzie, A. R.: The influence of particle composition upon the evolution of urban ultrafine diesel particles on the neighbourhood scale, University of Birmingham data repository, https://doi.org/10.25500/eData.bham.00000275, 2018.

Pugh, T. A. M., MacKenzie, A. R., Whyatt, J. D., and Hewitt, C. N.: Effectiveness of green infrastructure for improvement of air quality in urban street canyons, Environ. Sci. Technol., 46, 76927699, 2012.

Robinson,. A. L., Donahue, N. M., Shrivastava, M. K., Weitkamp, E. A., Sage, A. M., Grieshop, A. P., Lane, T. E., Pierce, J. R., and Pandis, S. N.: Rethinking organic aerosols: semivolatile emissions and photochemical aging, Science, 315, 1259-1262, 2007.

Ronkko, T., Lahde, T., Heikkila, J., Pirjola, L., Bauschke, U., Arnold, F., Schager, H., Rothe, D., Yli-Ojanpera, J., and Keskinen, J.: Effects of Gaseous Sulphuric Acid on Diesel Exhaust Nanoparticle Formation and Characteristics, Environ. Sci. Technol., 47, 11882-11889, 2013.

Stein, S. E. and Brown, R. L.: Estimation of normal boiling points from group contributions, J. Chem. Inf. Comp. Sci., 34, 581-558, 1994.

Topping, D., Barley, M., Bane, M. K., Higham, N., Aumont, B., Dingle, N., and McFiggans, G.: UManSysProp v1.0: an online and open-source facility for molecular property prediction and atmospheric aerosol calculations, Geosci. Model Dev., 9, 899914, https://doi.org/10.5194/gmd-9-899-2016, 2016.

US EPA: Estimation Programs Interface Suite ${ }^{\mathrm{TM}}$ for Microsoft ${ }^{\circledR}$ Windows, v 4.11, United States Environmental Protection Agency, Washington, DC, USA, 2017.

Wehner, B., Philippin, S., Wiedensohler, A., Scheer, V., and Vogt, R.: Variability of non-volatile fractions of atmospheric aerosol particles with traffic influence, Atmos. Environ., 38, 6081-6090, 2004.

Xia, M., Viera-Hutchins, L., Garcia-Lloret, M., Rivas, M. N., Wise, P., McGhee, S. A., Chatila, Z. K., Daher, N., Sioutas, C., and Chatila, T. A.: Vehicular exhaust particles promote allergic airway inflammation through an aryl hydrocarbon receptor-notch signaling cascade, J. Allergy Clin. Immun., 136, 441-453, 2015. 